
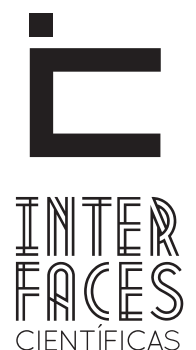

EDUCAÇÃO

ISSN IMPRESSO 2316-333X

ISSN ELETRÔNICO 2316-3828

\title{
A TEORIA DE PAULO FREIRE COMO FUNDAMENTO DA PEDAGOGIA SOCIAL
}

Karine Santos ${ }^{1}$

\section{RESUMO}

Este artigo tem como objetivo principal destacar em obras de Paulo Freire fundamentos relacionais com a Pedagogia Social, de modo a contribuir para reflexões em torno da temática formação do educador social no Brasil. A metodologia utilizada foi à revisão bibliográfica sobre obras de Paulo Freire e de estudiosos da Pedagogia Social. 0 artigo apresenta três categorias de análise: a inovação epistemológica, o engajamento político e a visão de mundo esperançosa que são componentes, tanto da Educação Popular, como da Pedagogia Social. Os resultados revelam que essas
Ercília Maria Angeli Teixeira de Paula²

categorias contribuem para a superação de condições opressoras e emancipação das pessoas através dos processos educacionais envolvidos nessas duas áreas. Para concluir, o artigo apresenta essas categorias como fundamentos para práticas educativas dos educadores sociais no Brasil.

\section{PALAVRAS-CHAVE}

Educação Popular. Pedagogia Social. Vulnerabilidade Social. Emancipação Social. 


\section{RESUMEN}

Este artículo tiene como principal objetivo subrayar en las obras de Paulo Freire los fundamentos que puedan hacer relación con la Pedagogía Social, para contribución de las reflexiones sobre la temática de la formación del educador social en Brasil. La metodología utilizada fue la revisión bibliográfica sobre las obras de Paulo Freire y de investigadores de la Pedagogía Social. El artículo presenta tres categorías del análisis: la innovación epistemológica, el compromiso político y la visión del mundo esperanzada, que son contenidos, tanto de la Educación Popular, como de la Pedagogía So- cial. Los resultados expresan que estas categorías contribuyen para la superación de las condiciones opresoras y emancipación de las personas por medio de los procesos educativos envueltos en estas dos áreas. Para concluir, el artículo presenta esas categorías como los fundamentos para las practicas educativas de los educadores sociales en Brasil.

\section{PALABRAS-CLAVE}

Educación Popular. Pedagogía Social. Vulnerabilidad Social. Emancipación Social.

\section{ABSTRACT}

This article aims to highlight the works of Paulo Freire relational foundations with Social Pedagogy in order to contribute to reflections around the theme of social educator training in Brazil. The methodology used was the literature review on works of Paulo Freire and scholars of Social Pedagogy. The article presents three categories of analysis: epistemological innovation, political engagement and hopeful vision of the world that are components of both the Popular Education as Social Pedagogy. The results show that these cat- egories contribute to overcoming oppressive conditions and empowerment of people through the educational processes involved in these two areas. To conclude, the article presents these categories as foundations for educational practices of social educators in Brazil.

\section{KEYWORDS}

Popular Education. Social Pedagogy. Social Vulnerability. Social Emancipation. 


\section{INTRODUÇÃO}

Paulo Freire situa-se na origem da Educação Popular enquanto um paradigma pedagógico inovador que emerge na América Latina e se afirma, hoje, como uma obra coletiva em processo de construção e reinvenção nas diferentes experiências de luta e organização das classes populares no mundo todo (ZITKOSKI, 2010a).

Reconhecemos que as propostas de Paulo Freire resistem à imposição do tempo e do espaço hegemônicos, tornando-se uma obra contemporânea. Entre ensinamentos como a leitura da palavra e a leitura do mundo, Freire nos deixou uma fecunda obra que se faz atual até os dias de hoje. Seu pensamento engajado, com força e criatividade que continua a nos provocar, principalmente para reinventá-lo. Dentre vários aspectos que poderíamos destacar, chamamos a atenção para as características mais marcantes, segundo nossa compreensão, do pensamento freiriano, que fazem de sua obra uma referência imprescindível a diferentes campos do saber: a inovação epistemológica; o engajamento político; a visão de mundo esperançosa e o seu significado na atualidade. Ainda que sem a intenção de tornar-se uma teoria institucionalizada, sua produção intelectual influenciou a formação de diferentes campos teóricos em nível internacional, como por exemplo, a Animação Sociocultural na Espanha; a Educação de Jovens e Adultos, os Programas Comunitários de Educação Social, Projetos de Educação Ambiental, Educação Social para pessoas com droga dependência, a Pedagogia Hospitalar, dentre outras perspectivas educacionais.

Atualmente, no Brasil, temos nos debruçado à compreensão da Pedagogia Social, especialmente, como forma de institucionalizar espaços de profissionalização e formação dos profissionais/educadores sociais que atuam no campo social. O campo social, em âmbito brasileiro, origina-se especialmente do atendimento a crianças e adolescentes em situação de vulnerabilidade social, na maioria das vezes vinculadas a Organizações Não Governamentais.
Entre aproximações, podemos dizer que a Educação Popular feiriana e a Pedagogia Social estão intimamente vinculadas quando destacamos seus aspectos fundamentais: por um lado a Educação Popular sempre esteve diretamente vinculada a movimentos de garantia e defesa por direitos sociais, por outro a Pedagogia Social busca um atendimento especializado àqueles que de alguma forma estão em desvantagem social. Ainda que reconheçamos as suas peculiaridades, especialmente quando visualizarmos os aspectos geográficos onde cada uma se desenvolveu, ambas, em diálogo poderão contribuir de forma significativa para a atual realidade do campo social.

De acordo com Paula (2014a), uma das semelhanças entre a Educação Popular e a Pedagogia Social se refere à educação como direito.

Segundo Paula (2014b, p. 6136) a Educação Popular no Brasil não é recente:

A Educação Popular nasceu no Brasil desde a década de 20 com o Manifesto dos Pioneiros da Escola Nova no qual os intelectuais brasileiros pregavam uma educação popular para todos. Todavia, somente na década de 60, devido ao processo de industrialização e urbanização é que o Brasil começou a se preocupar com os altos índices de analfabetismo de jovens e adultos das classes populares em função da necessidade de mão de obra qualificada para o trabalho. Os movimentos migratórios das pessoas em busca de melhores condições de vida eram constantes e este aspecto fez com que o Estado repensasse as políticas educacionais para as classes populares.

Na Educação Popular, como a dimensão pedagógica do próprio Movimento Popular, o processo de produção do saber é pedagogicamente mais importante do que o seu produto (BRANDÃO, 1995). Ela se interessa pela compreensão de como as pessoas se organizam para produzir e viver as experiências criadoras de conhecimentos. Desenvolve estratégias de educação que incentivam a participação, como um meio de promoção da cidadania, compreendida em suas dimensões crítica e ativa. 
Streck e Santos (2011) indicam que a Educação Popular faz da margem o seu lugar preferencial e historicamente tem revelado dificuldades de conviver com a institucionalidade. Muito se discutiu se a Educação Popular pode ser realizada na escola e os resultados das discussões parecem apontar para dois fatos aparentemente incompatíveis. Um deles, de que numa sociedade democrática a escola pode ser um lugar de educação popular, desde que propicie condições para os requisitos básicos da Educação Popular, tais como: tomar a realidade do educando como ponto de referência para o currículo; inserir-se numa proposta político-pedagógica transformadora no sentido da justiça social, da igualdade e do respeito da diferença; colocar o diálogo como princípio metodológico e epistemológico. 0 outro, que essa prática não pode ser "decretada" e por isso dificilmente a escola ou uma rede de escolas consegue praticar a Educação Popular. Essa sempre se realiza na tensão entre o instituído e o instituinte, portanto, nas fronteiras da institucionalidade.

Em relação à Pedagogia Social, tanto na Europa, como no Brasil, é preciso destacar que esta área tem procurado discutir o atendimento a todas as pessoas em condição de vulnerabilidade social, independente de classe social e condições econômicas. $\mathrm{Na}$ Europa, por exemplo, a Pedagogia Social atende pessoas de diferentes idades e classes sociais e, uma das suas características essenciais é que está voltada para a Terceira Idade. Com o aumento da expectativa de vida das populações de diferentes países e o envelhecimento da população mundial, novos desafios têm sido apresentados para o Estado que apresenta dificuldades em atender a essa população, tanto em termos de saúde, moradia e educação. Desta maneira, a Pedagogia Social tem buscado diferentes estratégias para atender a essas pessoas, independente de classe social.

No que se refere à história Educação Popular, é possivel perceber que, no Brasil, suas ações estão relacionadas aos movimentos sociais e de resistências aos sistemas opressivos e autoritários no período da ditadura e pós-ditadura militar. Um dos objetivos principais, nos primórdios da Educação Popular era de buscar promover a participação dos sujeitos na construção de um projeto político de sociedade por meio de soluções construídas coletivamente, nas quais se pretendia superar as desigualdades sociais.

Existem muitos estudiosos que têm procurado, há anos, difundir os ideais e conceitos da Educação Popular e de Paulo Freire no Brasil. Cabe destacar algumas obras de alguns destes estudiosos como: Brandão (1982, 2002), Garcia (1983), Gadotti (2007) e Streck (2006).

Na Educação Popular, como a dimensão pedagógica do próprio Movimento Popular, o processo de produção do saber é pedagogicamente mais importante do que o seu produto (BRANDÃO, 1995). Ela se interessa pela compreensão de como as pessoas se organizam para produzir e viver as experiências criadoras de conhecimentos. Desenvolve estratégias de educação que incentivam a participação, como um meio de promoção da cidadania, compreendida em suas dimensões crítica e ativa.

Conceitos como: resistência dos movimentos, interiorização da Educação Popular nas escolas e em práticas educativas diversificadas no campo e na saúde, o respeito ao saber popular, a afirmação da hegemonia de saberes, promoção da autonomia dos indivíduos, necessidade de ruptura com sistemas opressores, incorporação do saber erudito ao popular, paciência pedagógica, abertura para o conhecimento, preservação, criação e reelaboração de saberes, são elementos essenciais e muito enfatizados na Educação Popular.

Em relação à Pedagogia Social, encontramos pesquisadores em diferentes países que buscam difundir os ideários dessa concepção de educação. Dentre estes podemos destacar: Petrus (1997), Cabanas (1997), Nunez (1997), Machado (2014), Machado e Paula (2009), assim como Souza Neto, Silva e Moura (2009) e Graciani (2009). 
Petrus (1997), ao definir as características e expansão da Pedagogia Social na Espanha e na Europa nas últimas décadas, descreve que esta expansão é explicada por fatores diversos que surgiram no contexto social nestes últimos tempos como: novas políticas sociais, o advento da democracia, de novas formas de bem estar social e a consciência da responsabilidade frente aos novos problemas derivados da convivência nos grandes centros urbanos.

Para Petrus (1997, p. 10) “A democratização das sociedades e a demanda de serviços de proteção social tem ocorrido, possivelmente, como um dos principais fatores do desenvolvimento da Pedagogia Social”.

Na definição de Mollenhauer (1993, p. 28), a Pedagogia Social seria "[] o mais avançado campo experimental da sociedade, porque sua incumbência não é a de transmitir conteúdos culturais, mas exclusivamente ocupar-se com a superação de problemas emergentes das pessoas em formação com vistas a seu desenvolvimento e integração." Os olhos do educador estariam, assim, disponíveis para olhar e experimentar novas visões de futuro, uma sociedade que pudesse acolher a todos como cidadãos de fato e de direito (STRECK e SANTOS, 2011, p. 218).

A educação, tanto para a Educação Popular, como para a Pedagogia Social é concebida não somente como um modo de escolarização, mas como um processo político que contribui para a existência humana.

Segundo Streck e Santos (2011, p. 222), a Pedagogia Social, interessada na dinâmica das condições de vida de famílias, crianças, jovens, adultos e idosos, se insere no contexto dos problemas que surgem a partir da própria condição social. Numa perspectiva catalisadora de atividades que atingem a comunidade e a sociedade como um todo encontra no popular a referência que mobiliza a sua ação pedagógica.

Assim, esse artigo tem como objetivo destacar em obras de Paulo Freire fundamentos relacionais com a Pedagogia Social, de modo a contribuir para reflexões em torno da temática formação do educador social no Brasil.

A metodologia utilizada neste artigo foi a revisão bibliográfica e análise das obras de Paulo Freire e de pesquisadores da Pedagogia Social no Brasil e na Espanha.

Com uma obra que demonstra sempre atual, Freire faz um chamamento aos educadores em Pedagogia da Esperança, procurando anunciar caminhos que somente nós os educadores sociais sentimos quando estamos diante das pessoas com as quais nos encontramos cotidianamente. Dizia ele: "Hoje, mais do que em outras épocas, devemos cultivar uma educação da esperança enquanto empoderamento dos sujeitos históricos desafiados a superarmos as situações limites que nos desumanizam a todos" (FREIRE, 1994, p. 11).

É neste ritmo, que buscamos em Freire aproximações teóricas que contribuam para pensar uma Pedagogia Social originalmente brasileira, ainda que reconheçamos o Brasil como um país de muitas particularidades devido a sua dimensão territorial e cultural e passível de desenvolver e aprofundar diferentes Pedagogias sociais. Neste sentido, abordaremos três importantes aspectos da obra de Freire em relação com a Pedagogia Social: a inovação epistemológica, o engajamento político e a visão de mundo esperançosa. Concluindo com um item de desfecho, sobre o significado de Freire e sua obra na atualidade, conectando com a Pedagogia Social em discussão.

\section{A COMPOSIÇÃO TEÓRICA DE PAULO FREIRE}

Situar Freire no atual contexto da Pedagogia Social, especialmente em torno dessa discussão no Brasil, requer que se olhe com atenção a problemática da exclusão. E não estamos aqui querendo referir o termo exclusão como um conceito abstrato, tão amplo que não se consiga alcançar, mas sim, referindo 
o processo histórico de exclusão e negação de direitos que milhares de mulheres e homens, crianças e jovens passaram e vêm passando em nosso país. Tal especificidade direciona o olhar que queremos dar para a compreensão da teoria de Paulo Freire como fundamento da Pedagogia Social, no Brasil.

Aqui deixamos claro que Freire mantinha em sua rica produção teórica uma posição política quanto ao termo, partilhando da definição de Brandão (1980), que não desvincula da educação popular o seu sentido político e de classe que pressupõe: processo de libertação via conscientização e luta política.

De acordo com Torres (2013), a educação popular refere-se à interpretação crítica da realidade, logo possui um caráter gnosiológico; se posiciona diante da realidade e constrói alternativa, portanto possui um caráter político; orienta ações práticas e teóricas para a transformação de determinada realidade, é tanto individual quanto coletiva. Além disto, os sentidos e significados das experiências educativas populares encontram nas práticas e nos conhecimentos, potencial libertador. Não se trata de aplicação, mas de sua (re)criação e (re)invenção nos contextos e por meio das possibilidades temáticas em que estão situados os sujeitos.

Isso nos indica que a compreensão da teoria se dá como a própria prática refletida. A pedagogia é a explicitação de uma ação educativa enquanto "prática da liberdade" e de justiça social. O livro clássico de Paulo Freire, Pedagogia do oprimido, marca o protagonismo do sujeito que busca mudança na construção de sua pedagogia. Por isso já nesse livro são encontradas referências teóricas de distintas vertentes que, se não interpretadas a partir da prática, sugerem um diletantismo teórico. A rigorosidade, neste caso, não se assenta no enquadramento ao dogma de uma teoria ou a uma disciplina, mas nas exigências da prática.

\subsection{A INOVAÇÃO EPISTEMOLÓGICA}

A partir da proposição de análise da reflexão teórica em Freire, podemos dizer que uma contribuição fundamental é o desafio proposto pelo autor em trabalhar na perspectiva da realidade do oprimido. Como realidade, Freire considerava no social, no cultural, na história e na política aspectos importantes para a realização da leitura de mundo. Como afirma Zitkoski (2010b, p. 34) "a partir desse universo, o desafio dialógico-crítico converge para a luta em prol das transformações sociais necessárias e imprescindíveis para atingir uma vida mais digna, principalmente para os setores sociais mais oprimidos/excluídos."

Nas últimas décadas, no Brasil, existiram avanços e conquistas em relação aos direitos políticos e sociais para as pessoas excluídas e oprimidas em nosso país. Embora esses avanços tenham sido lentos e são criticados cotidianamente por elites conservadoras que desejam manter a mesma ordem social e excludente, os movimentos sociais e determinados segmentos políticos têm buscado propor políticas públicas sociais introduzindo novos conceitos de direitos.

Souza Neto (2009) descreve as contradições e os avanços da Pedagogia Social e das políticas sociais no Brasil, mais especificamente as políticas voltadas para crianças e adolescentes em condição de vulnerabilidade social. Ele considera que, durante longo período da história, essa parcela da população foi tratada como delinquentes e as soluções propostas pelo Estado eram de institucionalização e punição.

O Código de Menores (BRASIL, 1979) foi uma legislações que assumiu um caráter mais punitivo que educativo. As crianças e adolescentes em condição de vulnerabilidade social e suas famílias eram responsabilizados pela miséria e por condutas sociais "desviantes" derivadas das condições precárias e desumanas de vida. 
A Constituição de 1988 (BRASIL, 1988) e a doutrina da proteção integral do Estatuto da Criança e do Adolescente (BRASIL, 1990) trouxeram avanços das garantias sociais e no modo de tratar as crianças e adolescentes como sujeitos de direitos. É preciso lembrar que essas legislações foram resultantes de lutas sociais.

Souza Neto (2009) apresenta a influência de Paulo Freire na proposição esperançosa desses direitos para as crianças e adolescentes no Brasil e a modificação do papel do Estado quando descreve uma fala de Freire no Seminário Internacional da Criança e do Adolescente de Baixa Renda realizado em São Paulo em 1989. Neste seminário, Freire discutia a importância que as crianças e adolescentes assumem no momento que são tratados com dignidade e auxiliam a sociedade a se redescobrir:

Os meninos e meninas estão inventando outro país, e, nós, mais velhos, temos que ajudar essas meninas e esses meninos a refazer o Brasil. E é com convicção, é com esse sonho que eu falo: ajudemos estes meninos a reinventar o mundo. (FREIRE, 1989, p. 9 apud SOUZA 2009, p. 268).

Desta maneira, é possível perceber as contribuições de Paulo Freire para a modificação do conceito de crianças e adolescentes como sujeitos protagonistas da história e as influências deste conceito para a formação dos educadores sociais no Brasil.

As legislações voltadas para a garantia dos direitos desses cidadãos precisam ser amplamente discutidas, analisadas e internalizadas pelos educadores sociais na busca de "outras Pedagogias" possíveis e nas transformações de relações sociais opressoras e discriminatórias.

Souza Neto (2009, p. 269), também, discute as posições conservadoras na sociedade brasileira que precisam ser revistas, principalmente para aquelas pessoas que desejam trabalhar com a Pedagogia Social no Brasil:

\begin{abstract}
A cultura opressora e autoritária que ainda toma conta da sociedade brasileira emperra a passagem do mal ao bem estar social. É uma sociedade em que os direitos sociais e econômicos são sonegados para a maioria da população, que é tratada pelo viés de uma cidadania de segunda classe, tutelada pelo Estado. 0 desafio que se coloca é articular as esperanças subjetivas existentes em cada indivíduo e na sociedade com as oportunidades objetivas advindas das políticas sociais e econômicas.
\end{abstract}

Ao estudar as relações entre Educação Popular e Pedagogia Social, Machado (2014, p.134) dialoga com pesquisadores da Pedagogia Social que discutem a abrangência da Pedagogia Social:

Ainda em relação à defesa de que a Educação Popular deva ser para todos e não apenas a grupos pobres, Silva (2009) fundamentado em Paulo Freire, afirma que a Pedagogia Social não pode ser destinada apenas para os oprimidos, mas também aos opressores, pois como defendido por Freire em Pedagogia do Oprimido (1978), é por meio da comunhão entre os homens e de sua conscientização critica da realidade que o oprimido deixa de ser oprimido e o opressor deixa de ser opressor.

Sendo assim, uma das condições para superação dessas condições opressoras e autoritárias é o engajamento político em diferentes âmbitos e com diferentes pessoas de todas as classes sociais, aspectos este que discutiremos a seguir.

\subsection{O ENGAJAMENTO POLÍTICO}

O posicionamento político em Freire é muito evidente. 0 político em Freire está na opção de vincular o olhar pedagógico humanizador à realidade social, pois considera o autor que isso leva a denúncia da realidade perversa. "Toda educação é política”, afirma Freire (1993, p. ?), pois considera que toda educação é uma prática social e, dessa forma, está comprometida com a transformação dos sistemas opressores e, portanto, em busca da libertação.

Esse engajamento político que Freire defende diz respeito à vinculação necessária entre as práticas pe- 
dagógicas e a defesa de direitos, por exemplo, ou ainda, a um projeto de sociedade que defendemos.

Nos princípios da Educação Popular e da Pedagogia Social, o engajamento político dos educadores e educandos é uma questão essencial. Durante muitos anos no Brasil a Educação Popular foi criticada por ser considerada "espontaneísta" por muitos pesquisadores que não conseguem compreender os significados e as formas específicas de construção da cidadania e democracia em nosso país. Essas críticas não reconhecem os valores e as dificuldades quando se trabalha com processos democráticos. 0 exercício da democracia é árduo e exige consciência política, partilhas, conflitos e consensos.

Nunez (2009, p. 251) ao discutir a necessidade de participação política na Educação Social afirma que:

A Educação Social, quando possibilita as pessoas se posicionarem, encontra com uma afirmativa de Aristóteles que ensinava que existem lugares que a ética desemboca na política. Entre esses, estão as coordenadas do exercício da educação plena. 0 reconhecimento deste direito é o exercício da cidadania. E a cidadania é como uma possibilidade dos exercícios de direitos e deveres.

Petrus (1997, p. 27) considera que a Pedagogia Social como formação política do cidadão precisa abranger três aspectos:

a) Como formação das capacidades sociais dos cidadãos para uma correta convivência social,

b) Como atuações escolares e extraescolares

c) Como um sistema de ajuda social e cultural principalmente nas áreas mais conflitivas. É o trabalho social educativo e não assistencial.

Tanto a Educação Popular como a Pedagogia Social discutem a necessidade de modificar as relações desiguais e opressoras existentes nas sociedades. Embora para muitos, essas questões possam parecer inatingíveis, elas não o são para quem acredita nos seres humanos e nas transformações sociais. Para tanto, a visão esperançosa de Paulo Freire para a construção de uma sociedade digna contribuem para o enfrentamento de concepções fatalistas e derrotistas para a humanidade.

\section{A VISÃO DE MUNDO ESPERANÇOSA}

A visão de mundo que reforça o valor do sonho e da utopia numa perspectiva da história como possibilidade é coerente com os princípios da Educação Popular como caminho para a emancipação dos oprimidos. Isso representa considerar o ser humano como um ser histórico e social.

Graciani (2009), pesquisadora da Pedagogia Social que há muitos anos trabalha com crianças e adolescentes de rua, em condições extremas de vulnerabilidade social, defende uma concepção esperançosa e política para a educação. Essa pesquisadora propõe passos metodológicos expressivos para lidar com as crianças e adolescentes de forma amorosa e esperançosa. Dentre esses passos estão: a desterritorializacão do educador social de valores preconceituosos, a necessidade da escuta, a consciência do momento de cada criança e adolescente, a necessidade de preservação da privacidade dessas pessoas, a paciência pedagógica e a clareza que o processo educativo não é linear, mas repleto de conflitos e contradições.

Graciani (2009, p. 222), ao discutir a visão de mundo esperançosa na Pedagogia Social considera que:

\begin{abstract}
Muitas são as dimensões e vertentes do fazer educativo que atendem as necessidades básicas do fazer educativo que atendem as necessidades básicas da aprendizagem; no entanto, as que privilegiam a vida, o ser humano como sujeito de sua própria história, a construção do conhecimento e da história social de sua comunidade e da sociedade como totalidade, são as que provavelmente contribuirão para uma prática educativa emancipadora e libertadora de nosso povo.
\end{abstract}

As influências teóricas que foram sendo agregadas ao contexto da educação popular se mantêm 
em relação contraditória, muitas vezes, com as anteriores, revelando marcas do caráter conflitante que a perpassa e constitui, afirmando-a como um processo dialético e, ao mesmo tempo, dialógico. A dialética pode ser considerada como sua característica marcante em meio ao movimento histórico de vir-a-ser. Neste sentido, discutir o tema da educação popular na sua relação com a pedagogia social alicerçada na obra de Paulo Freire concretiza a dinâmica existente no campo social, demonstrando o quanto ainda precisamos nos debruçar no entendimento de cada uma dessas perspectivas teórico-práticas em busca de contribuições que ajudem a acessar, compreender e intervir de modo eficaz nos problemas sociais em nosso país.

\section{5 À GUISA DE CONCLUSÃO}

A obra de Freire e os estudiosos da Pedagogia Social no Brasil inspiram processos socioeducativos inovadores. A proposta reafirmada pelo autor, e por esses estudiosos a respeito de uma educação problematizadora, converge com os desafios concretos no campo social hoje. O legado de Freire está intimamente articulado com os movimentos sociais, especialmente nos anos de 1960 e 1970. Por isso, levar em consideração determinadas características facilita o direcionamento do que queremos focar enquanto uma Pedagogia Social originalmente brasileira. Dessa forma, consideramos fundamental propor duas questões: Qual é o nosso olhar sob nós mesmos? Qual é o olhar que pretendemos ter como educadores sociais sob as questões sociais que tanto nos afligem?

A epistemologia do campo educativo precisa pensar um corpo de conhecimentos transdisciplinares que opere sobre o social, potencializando uma educação para a cidadania pautada na solidariedade. Uma educação voltada para a vida, para a paz, para a efetiva inclusão social, demanda, portanto, uma pedagogia da complexidade que, pela sua dimensão ético-político-estética, concretiza uma educação comprometida com o cuidado, com o bem viver coletivo e com a liberdade.

Essas considerações podem contribuir de fato com a proposição de ações verdadeiramente impactantes na realidade dos sujeitos com os quais lidamos no campo social. Vinculando a nossa história de lutas travadas pela educação popular com as propostas técnicas advindas da pedagogia social certamente encontraremos caminhos sólidos para que uma pedagogia social original aconteça.

A Educação Popular defende uma educação sócio-transformadora, onde a práxis é elemento fundamental para a efetiva transformação do homem, da sociedade e do Estado. A Pedagogia Social interessada na dinâmica das condições de vida de famílias, crianças, jovens, adultos e idosos, se insere no contexto dos problemas que surgem a partir da própria condição social. No entanto, cabe a nós educadores superar os discursos de maneira que as práticas constituam sentido transformador das realidades que afligem a nossa sociedade.

\section{REFERÊNCIAS}

BRANDÃO, Carlos R.(org) O Educador: Vida e Morte. Rio de Janeiro: Graal, 1982.

BRANDÃO, Carlos R. Educação como cultura. Campinas: São Paulo; Mercado das Letras, 2002.

BRANDÃO, Carlos R. Em campo aberto: escritos sobre educação popular. São Paulo: Cortez, 1995.

BRANDÃO, Carlos R. A educação como Cultura. São Paulo: Brasiliense, 1980.

BRASIL. Código de Menores. Disponível em: <http:// www.planalto.gov.br/ccivil_03/leis/1970-1979/ L6697.htm>. Acesso em: 2 maio 2014 
BRASIL. Constituição da República Federativa do Brasil de 1988. Disponível em: <http://www.planalto.gov.br/ccivil_03/constituicao/constituicao.htm>. Acesso em: 2 maio 2014

BRASIL. Estatuto da Criança e do Adolescente promulgado em 13 de julho de 1990. Belo Horizonte: VL\&P, 1990, 135p.

CABANAS, José Maria Quintana. Antecedentes históricos de La educacion social. In: PETRUS, Antonio (coordinador). Pedagogía Social. Barcelona: Ariel, 1997, p.68-90

FREIRE, Paulo. Pedagogia do Oprimido. São Paulo: Paz e Terra, 1993.

FREIRE, Paulo. Pedagogia da Esperança. São Paulo: Paz e Terra, 1994.

GADOTTI, Moacir. Perspectivas atuais da educação. Disponível em:

<http//:www.scielo.br/pdf/ssp/v14n2/9782.pdf>. Acesso em: 3 mar. 2013.

GARCIA, Pedro B. Saber popular e Educação Popular. Cadernos de Educação

Popular. Petrópolis, Rio de Janeiro: Vozes, 1983.

GRACIANI, Maria Stela. A Pedagogia Social no Trabatho com crianças e adolescentes de rua. In: João Clemente; SILVA, Roberto; MOURA, Rogério. Pedagogia Social. São Paulo: Expressão e Arte, 2009, p.207-224.

MACHADO, Erico Ribas. As relações entre a Pedagogia Social e a Educação Popular no Brasil. Disponível em: <http://www.proceedings.scielo.br/pdf/cips/ n4v1/24.pdf>. Acesso em: 6 maio 2014.

MOLLENHAUER, Klaus. Einführung in die Sozialpädagogik: Probleme und Begriffe der Jugendhilfe.10. Auflage. Weinheim und Basel: Beltz, 1993.
NUNES, Violeta. Participación y Educación Social. In: SOUZA NETO, João Clemente; SILVA, Roberto; MOURA, Rogério. Pedagogia Social. São Paulo: Expressão e Arte, 2009, p. 241-256

PAULA, Ercília Maria Angeli Teixeira. Dilemas e contradições entre projetos de Educação Não Formal com a Educação Popular: Reflexões sobre práticas e saberes. Disponível em: <http://30reuniao.anped.org.br/trabalhos/GT06-3264--Int.pdf>. Acesso em: 4 maio 2014.

PAULA, Ercília Maria Angeli Teixeira. Educação Popular, Educação Não Formal e Pedagogia Social: Análise de conceitos e implicações para a Educação Brasileira e Formação de professores. Disponível em: <http:// www.pucpr.br/eventos/educere/educere2009/anais/ pdf/2103_1034.pdf>. Acesso em: 5 maio 2014.

PAULA, Ercilia Maria Angeli Teixeira; MACHADO, Erico Ribas. A Pedagogia Social na Educação: análise de perspectivas de formação e atuação dos educadores sociais no Brasil. Disponível em: <http://www.proceedings.scielo.br/scielo.php?pid=MSC000000009200800 0100005\&script=sci_arttext>. Acesso em: 5 maio 2014.

PETRUS, Antonio (coor.). Pedagogía Social. Barcelona: Ariel, 1997

SOUZA NETO, João Clemente de. Pedagogia Social e as Políticas Sociais no Brasil. In: SOUZA NETO, João Clemente; SILVA, Roberto; MOURA, Rogério. Pedagogia Social. São Paulo: Expressão e Arte, 2009, p.257-272

STRECK, Danilo R. A educação popular e a re(construção) do público. Há fogo entre as brasas? Revista Brasileira de Educação. ANPED, Associação Nacional de Pós Graduação e Pesquisa em Educação, v.11, n.32, maio/ago. 2006, p.272-284.

STRECK, Danilo R.; SANTOS, Karine. Educação de Jovens e Adultos: Diálogos com a Educação Popular e Pedagogia Social. EccoS - Revista Científica, n. 25, São Paulo, jan./jun. 2011, p.19-37. 
TORRES CARRILO, Alfonso. A educação popular como prática política e pedagógica emancipadora. In: STRECK, Danilo R.; ESTEBAN, Maria Teresa (orgs.). Educação Popular: lugar de construção social coletiva. Petrópolis, RJ: Vozes, 2013.

ZITKOSKI, Jaime José. Paulo Freire e a Educação. Belo Horizonte: Autêntica, 2010a.
ZITKOSKI, Jaime José. Educação Popular: raízes históricas e temas emergentes, uma leitura a partir de Paulo Freire. In: SCHINELO, Edmilson; CHAMORRO, Graciela; ZITKOSKI, Jaime José. Teologia da Libertação e Educação Popular: Raízes e asas. São Leopoldo: Contexto, 2010b. 